\title{
ANALISIS QUALITY CONTROL DALAM PROSES PENGOLAHAN TEH HITAM DENGAN METODE SIX SIGMA
}

\author{
Irsan, Henny Yulius \\ Universitas Putra Indonesia YPTK Padang \\ E-mail: Irsan@upiyptk.ac.id, hennyyulius@upiyptk.ac.id
}

\begin{abstract}
Abstrak
PT. Perkebunan Nusantara VI Unit Usaha Danau Kembar yang merupakan salah satu perusahaan Badan Usaha Milik Negara yang bergerak dibidang industri perkebunan teh hitam. Penelitian ini bertujuan untuk menganalisa kualitas proses pengolahan teh hitam yang menyimpang (cacat) atau rework pada stasiun kerja pengeringan dengan menggunakan metode pengendalian kualitas Six Sigma melalui konsep DMAIC.

Hasil penelitian ini menunjukan bahwa nilai sigma yang didapatkan untuk produksi teh hitam jenis PF (Pecco Fanning) memiliki nilai sigma 3,2661 (3-sigma) dengan nilai DPMO sebesar 38690. Hal ini menunjukkan bahwa setiap satu juta kesempatan akan terdapat kemungkinan 38690 unit ketidaksesuian/produk rework. Penyebab rewok pada produk dipengaruhi oleh faktor manusia, mesin, lingkungan kerja serta metode kerja yang dilakukan.
\end{abstract}

Kata kunci: Pengendalian Kualitas, Six Sigma, DMAIC

\section{Pendahuluan}

Dalam era perdagangan bebas, pelaku dunia industri akan menghadapi persaingan ketat dengan produsen lain dari seluruh dunia. Dengan meningkatnya intensitas persaingan dan jumlah pesaing, hal ini menuntut agar setiap produsen memenuhi kebutuhan konsumen dengan cara yang lebih memuaskan daripada yang dilakukan oleh para pesaing lain, sehingga dalam perdagangan global ini diperlukan suatu persamaan persepsi dalam mendefinisikan suatu produk. Standar mutu yang selaras antar negara pada akhirnya merupakan kebutuhan yang tidak dapat dihindari. Oleh karena itu kualitas merupakan faktor penting bagi produsen. Namun perhatian produsen tidak terbatas pada kualitas produk yang dihasilkan saja tetapi juga pada aspek proses, sumber daya manusia dan lingkungan. Sedangkan lingkungan yang dihadapi produsen semakin kompleks dan hanya produsen yang benar-benar berkualitas yang dapat bersaing dalam pasar global. Persaingan di pasar Internasional hanya akan dimenangkan oleh perusahaan yang adaptif dan memiliki keunggulan dalam memenuhi kebutuhan konsumen. Kompleksitas persaingan global juga menyebabkan setiap produsen untuk selalu berusaha meningkatkan kualitas agar memenuhi kebutuhan konsumen. PTPN VI merupakan salah satu Badan Usaha Milik Negara yang bergerak dibidang industri perkebunan, mengusahakan komoditas kelapa sawit, karet, dan teh. Luas areal konsesi teh yang ada di PTPN VI Unit Usaha Danau kembar yaitu 669,26 hektar yang terdiri dari 2 afdeling. PTPN VI Unit Usaha Danau Kembar menghasilkan teh dengan jenis orthodox atau teh hitam. Teh yang dihasilkan di ekspor keluar negeri. Negara pemasaran teh PTPN VI Unit Usaha Danau Kembar yaitu Jerman, Inggris, Australia, Amerika Serikat, Pakistan, Timur Tengah, Singapura, Afganistan, Belanda, India, Kanada, Malaysia, Jepang, Rusia, Polandia, Ukraina, dan Arab. Produksi teh jadi PTPN VI Unit Usaha Danau Kembar berfluktuasi dan cenderung menurun. Salah satu yang mempengaruhi penurunan tersebut tidak terlepas dari kualitas teh hitam yang dihasilkan pada saat proses pengolahan teh hitam. 


\section{Tinjauan Literatur}

\subsection{Pengendalian Kualitas}

Kualitas merupakan upaya dari produsen untuk memenuhi kepuasan pelanggan dengan memberikan apa yang menjadi kebutuhan, ekspektasi, dan bahkan harapan dari pelanggan, dimana upaya tersebut terlihat dan terukur dari hasil akhir produk yang dihasilkan ${ }^{[1]}$. Menurut Assauri ${ }^{[2]}$, manfaat melakukan pengendalian kualitas secara statistik antara lain:

1. Pengendalian (control), di mana penyelidikan yang diperlukan untuk dapat menetapkan statistical control mengharuskan bahwa syarat-syarat kualitas pada situasi itu dan kemampuan prosesnya telah dipelajari hingga mendetail. Hal ini akan menghilangkan beberapa titik kesulitan tertentu, baik dalam spesifikasi maupun dalam proses.

2. Pengerjaan kembali barang-barang yang telah scrap-rework. Dengan dijalankan pengendalian, maka dapat mencegah terjadinya penyimpangan-penyimpangan dalam proses. Sebelum terjadi hal-hal yang tidak diharapkan dan akan diperoleh kesesuaian yang lebih baik antara kemampuan proses (process capability) dengan spesifikasi, sehingga banyaknya barang-barang yang cacat (scrap) dapat dihindari. Kasus yang dihadapi perusahaan saat ini, biaya-biaya bahan sering kali mencapai 3 sampai 4 kali biaya buruh, sehingga dengan perbaikan yang telah dilakukan dalam hal pemanfaatan bahan dapat memberikan penghematan yang menguntungkan.

3. Biaya-biaya pemeriksaan, karena Statistical Quality Control dilakukan dengan jalan mengambil sampel-sampel dan mempergunakan teknik sampling, maka hanya sebagian saja dari hasil produksi yang perlu untuk diperiksa. Akibatnya maka hal ini akan dapat menurunkan biaya-biaya pemeriksaaan.

Setiap metode perbaikan kualitas tentu ditunjang oleh alat-alat bantu yang disebut "Alat-alat Kualitas" atau "Quality Tools". Berikut adalah alat-alat kualitas yang digunakan pada perbaikan kualitas $^{[1]}$.

1. Cause Effect Diagram

Cause Effect Diagram atau Diagram Sebab Akibat dikemukakan pertama kali oleh Prof.Dr. Kouru Ishikawa. Kaouru Ishikawa adalah seorang Insinyur Teknik Kimia. Secara umum diagram sebab akibat adalah gambaran grafis yang menampilkan mengenai faktor penyebab dari kegagalan atau ketidaksesuaian, hingga menganalisa ke bagian sub paling dalam dari faktor penyebab timbulnya masalah. Bentuk analisa pada Cause Effect Diagram adalah bentuk data yang secara dominan dikumpulkan dengan cara subjektif dan analisa yang terjadi berasal dari hal-hal obyektif atau subyektif dengan menggunakan data kuantitatif atau kualitatif. Analisa yang dibangun haruslah berasal dari pengamat-pengamat atau orang kompeten pada area yang dibahas.

2. Check Sheet

Lembar Check Sheet adalah alat untuk memastikan kualitas secara real time, artinya adalah isian pada lembar Check Sheet akan memberikan gambaran aktual dan terkini mengenai kualitas. Kebenaran data sangatlah tergantung kepada orang atau petugas yang menilai kondisi di lapangan. Lembar Check Sheet memiliki dua tipe isian yang paling umum digunakan yakni menggunakan tanda centang dan tanda garis. Lembar Check Sheet dengan tanda centang digunakan untuk memastikan kualitas dari segi kualitatif atau digunakan pada pengecekan data kualitas yang bersifat atribut, artinya adalah penilai hanya mengecek kesesuaian data lapangan dengan data yang seharusnya, meskipun kemudian data yang dicek adalah data variabel. Lembar Check Sheet dengan tanda garis digunakan untuk memastikan kualitas pengamatan dengan cara kuantitatif, yang dimaksud kuantitatif adalah si penilai melakukan perhitungan atas obyek yang sedang diamati, kesesuaian antara harapan dan kenyataan diukur tidak hanya dengan mengamati, namun ada proses menghitung secara langsung.

3. Diagram Pareto

Vilfredo Federico Damaso Pareto, seorang ekonom dan sosiolog yang lahir pada 15 Juli 1848 di Paris. Ia adalah orang yang mengemukakan konsep efisiensi pareto dan hukum 
pareto yang menyatakan bahwa $80 \%$ dari akibat atau dihasilkan oleh $20 \%$ penyebab. Atau bisa juga diartikan dengan $80 \%$ hasil usaha yang produktif dan optimal. Pareto kemudian mengembangkan sebuah diagram untuk memetakan faktor-faktor penyebab sebuah masalah, kemudian pemecahan masalah haruslah berfokus atau memprioritaskan $80 \%$ penyebab mayoritas. Manfaat yang akan diperoleh dari menggunakan diagram pareto adalah seorang analis akan mengetahui gambaran statistik penyebab masalah yang menjadi fokus awal untuk dipecahkan.

4. Histogram

Histogram adalah satu alat didalam metode implementasi perbaikan kualitas yang berfungsi untuk memetakan distribusi atas sejumlah data. Kata histogram berasal berasal dari kosa kata Yunani "Histos" dan "Grama". Histogram merupakan instrumen penting di dalam statistik yang juga capable digunakan sebagai Quality Tools.

5. Scatter Plots

Seiring munculnya persepsi dan asumsi bahwa kualitas sebuah proses sering kali memiliki hubungan dengan hal-hal lain di dalam proses produksi. Sebagai contoh adalah sering kali jumlah produk yang cacat diakibatkan oleh tidak optimalnya penglihatan operator disebabkan oleh intesitas cahaya yang terlalu tinggi. Scatter Plots atau sering disebut Scatter Diagram merupakan alat di dalam metode penerapan perbaikan kualitas yang berfungsi untuk memberikan gambaran tentang sebesar apakah sesuatu variabel memiliki ikatan atau korelasi dengan variabel lainnya.

6. Peta Kontrol

Peta kontrol atau biasa disebut juga dengan Peta kendali pertama kali diperkenalkan oleh Dr. Walter Andrew Shewhart pada tahun 1924 di Bell Telephone Laboratories, Amerika Serikat dan merupakan alat interprestasi kualitas yang paling banyak dan secara luas digunakan. Peta kontrol digunakan untuk mengetahui apakah suatu proses berada dalam batas kendali atau apakah kapabilitas sebuah proses berada pada batas dan kriteria yang diharapkan. Apabila terdapat objek pengamatan yang di plot berada keluar dari batas kendali, pada kasus tertentu bukan berarti objek pengamatan tersebut tidak berkualitas, namun kapabilitas proses yang terjadi tidak mampu menjaga agar hasil akhir berada pada batas kendali yang diharapkan.

Dalam pengendalian produk akhir, peta kendali membatasi toleransi penyimpangan yang masih dapat diterima, baik karena akibat kelemahan tenaga kerja, mesin dan sebagainya. Peta kendali dapat diklasifikasikan kedalam dua tipe umum. Apabila karakteristik kualitas dapat diukur dan dinyatakan dalam bilangan, biasanya dinamakan peta kendali variabel. Peta kendali variabel terdiri dari peta kendali untuk mean $(x)$ dan peta kendali untuk rentang (R) atau rentang bergerak (MR). Untuk karakteristik kualitas yang tidak diukur dengan skala kuantitatif, digunakan penilaian unit produk sebagai sesuai atau tidak sesuai atas dasar apakah produk itu memiliki atau tidak memiliki sifat tertentu, atau kita dapat mencacah banyaknya yang tidak sesuai (cacat) yang tampak pada suatu unit produk. Peta kendali untuk karakteristik kualitas semacam itu dinamakan peta kendali atribut. Peta kendali atribut terdiri dari peta kendali untuk bagian tak sesuai (p), peta kendali untuk ketidaksesuaian (c), dan peta kendali untuk ketidaksesuaian per unit (u).

7. Flow Chart

Salah satu alat dalam implementasi metode perbaikan kualitas yang berorientasi dan memetakan proses adalah Flow Chart. Flow chart merupakan management tools yang digunakan untuk memetakan proses atau tahapan-tahapan dari sebuah proses. Flow chart secara harfiah diterjemahkan sebagai diagram alir yang menunjukan alir dari sebuah proses. Dengan menggunakan flow chart, alur dari sebuah proses akan dapat lebih mudah dipahami sehingga dapat ditarik sebuah analisa mengenai sebab dan akibat apabila kemudian diperoleh sebuah hasil yang dianggap diluar batas toleransi. 


\subsection{Six Sigma}

Menurut Hendy Tannady ${ }^{[1]}$, secara umum Six Sigma memiliki 2 pengertian, yakni Six Sigma sebagai filosofi bagi perbaikan berkelanjutan dengan terus mereduksi produk cacat dan Six Sigma sebagai alat teknis dalam mengukur jumlah cacat per 1 juta produk yang dihasilkan.

Six Sigma merupakan konsep statistik yang mengukur suatu proses yang berkaitan dengan cacat atau kerusakan. Mencapai enam sigma berarti bahwa suatu proses menghasilkan hanya 3,4 cacat per sejuta peluang. Six Sigma juga diartikan sebagai falsafah manajemen yang berfokus untuk menghapus cacat dengan cara menekankan pemahaman, pengukuran, dan perbaikan proses ${ }^{[3]}$.

\subsection{Siklus DMAIC}

Konsep DMAIC (Define-Measure-Analyze-Improve-Control) merupakan metode yang paling umum digunakan untuk mengukur penerapan Six Sigma didalam sebuah organisasi. DMAIC adalah sekumpulan alat yang digunakan untuk megidentifikasi, analisis dan mengeliminasi sumber variasi dalam sebuah proses ${ }^{[4]}$. DMAIC dimulai dengan proses Define (Identifikasi), Measure (Pengukuran), Analyze (Analisa), Improve (Perbaikan) dan Control (Pengendalian). Pada masa selanjutnya setiap kegiatan improvisasinya yang dapat dijadikan best practice akan distandarisasi agar dapat digunakan sebagai pedoman pada kerja berikutnya. Standarisasi inilah yang kemudian sering ditambahkan kedalam DMAIC menjadi DMAICS (Define-MeasureAnalyze-Improve-Control-Standarized $)^{[1]}$.

Secara umum metodologi implementasi DMAIC ditunjukan pada gambar berikut ${ }^{[1]}$ :

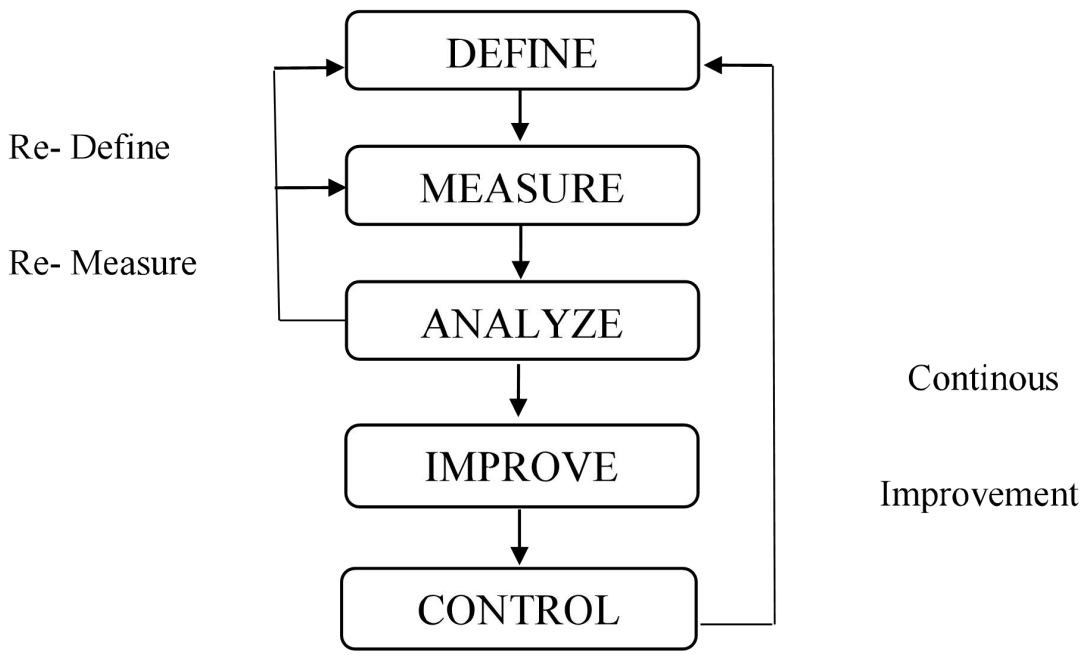

Gambar 1: Siklus DMAIC ${ }^{[1]}$

1) Define

Tahap Define merupakan tahap identifikasi awal, dimana pada tahap ini organisasi haruslah akurat dan jeli dalam melihat dampak dan permasalahan yang timbul. Tahap ini pada umumnya dimulai dengan membuat Six Sigma Charter menentukan deskripsi dari CTQ) (Critical to Quality). Langkah ini mendefinisikan rencana-rencana tindakan (Action Plan) yang harus dilakukan untuk melaksanakan peningkatan dari setiap tahap proses

2) Measure

Pengkuran terhadap kualitas produk akhir dari existing process merupakan parameter bagaimana menilai kapabilitas proses yang berjalan saat ini. Pada tahap measure, tools yang umum digunakan adalah peta control. Dengan peta kontrol akan diketahui hasil akhir yang menyimpang dari batas atas atau batas akhir kriteria produk yang ditetapkan perusahaan. Pada tahap pengukuran (measure) dilakukan pengukuran level Sigma yang dilakukan 
dengan mengkonversikan hasil jumlah kecacatan dalam Defect per Million Opportunities (DPMO) ke dalam level sigma. Berikut adalah tahap -tahap dalam melakukan pengukuran:

a. Pengumpulan Data CTQ (Critical to Quality).

CTQ merupakan batas, karakteristik dan standar kualitas atas dimensi-dimensi kualitas yang harus dijaga dari sebuah poduk. Standar atas dimensi ini bias merupakan masukan yang datang dari konsumen atau ditetapkan oleh produsen. CTQ memberikan analisa terhadap hal-hal baik dalam dan luar perusahaan yang memiliki potensi memengaruhi dimensi-dimensi kualitas dari produk.

b. Defect per Million Opportunities (DPMO)

Defect adalah kegagalan untuk memberikan apa yang diinginkan oleh pelanggan. Sedangkan Defect Per Oppurtunities (DPO) merupakan ukuran kegagalan yang dihitung dalam program peningkatan kualias Six Sigma, yang menunjukan banyaknya cacat atau kegagalan per satu kesempatan dan dihitung dengan formula berikut:

$$
\text { DPO }=\frac{\text { Total Kerusakan }}{\text { Total Produksi } x \text { CTQ }}
$$

Besarnya DPO ini apabila dikalikan dengan konstanta 1.000.000 akan menjadi formula DPMO berikut:

$$
D P M O=D P O X 1.000 .000
$$

Defect per Million Oppurtunities (DPMO) merupakan ukuran kegagalan dalam program peningkatan Six Sigma, yang menunjukkan kegagalan per satu juta kesempatan.

3) Pengukuran Level Sigma

Level Sigma salah satu parameter kunci keberhasilan penerapan konsep Six Sigma dapat dilihat dari hasil perhitungan level Sigma pada output proses yang merupakan ukuran pencapaian target menuju tingkat kegagalan nol (zero defect). Semakin tinggi level Sigma akan membuat tingkat kecacatan yang diproduksi per satu juta kesempatan (DPMO) semakin rendah, sehingga produk tersebut akan semakin memenuhi ekspektasi dari pelanggan.

$$
\text { Level Sigma }=\left(\frac{1.000 .000 \times D P M O}{1.000 .000}\right)+1,5
$$

4) Pengukuran Stabilitas

Proses pada bagian ini dilakukan stabilitas proses dimana proses ini menggambarkan kondisi proses untuk menghasilkan suatu produk yang nilainya stabil (tidak mudah berubah) dari waktu ke waktu. Tahap ini dilakukan untuk mengetahui apakah suatu proses telah stabil dimana stabilitas ini merupakan syarat untuk perhitungan kapabilitas proses. Tools yang digunakan untuk mengidentifikasi stabilitas proses adalah menggunakan peta kendali proses. Penelitian ini menggunakan peta kendali $\mathrm{p}$ dimana peta ini digunakan untuk mengukur proporsi jumlah unit cacat. Langkah-langkah pembuatan peta kendali $p$ antara lain:

a) Sampel yang digunakan bervariasi untuk melakukan setiap kali melakukan pengetesan

b) Menghitung proporsi total cacat (p)

$$
p=\frac{\text { jumlah cacat }}{\text { unit yang diinspeksi }}
$$


c) Menghitung rata-rata dari $\mathrm{p}$ (proporsi total cacat)

$$
\bar{p}=\frac{\text { total cacat }}{\text { total inspeksi }}
$$

d) Menghitung batas kendali untuk peta kendali $\mathrm{p}$

Penentuan Upper Control Limit

$$
U C L=\bar{p}+3 \sqrt{\frac{\bar{p}(1-\bar{p})}{n}}
$$

Penentuan Lower Control Limit

$$
L C L=\bar{p}-3 \sqrt{\frac{\bar{p}(1-\bar{p})}{n}}
$$

dimana:

$$
\begin{array}{ll}
\mathrm{CL} & =\text { Center Line (Garis Pusat) } \\
\mathrm{UCL} & =\text { Upper Control Limit (Batas Kendali Atas) } \\
\mathrm{LCL} & =\text { Lower Control Limit (Batas Kendali Bawah) } \\
\mathrm{P} & =\text { Mean bagian yang rusak pada Sampel } \\
\mathrm{N} & =\text { Ukuran setiap Sampel }
\end{array}
$$

5) Analyze

Ketika hasil akhir tidak sesuai dengan apa yang direncanakan dan ditargetkan diperlukan sebuah analisa atas hasil dan proses yang telah berlangsung. Tahap Analyze DMAIC berfungsi untuk memberikan masukan atau prioritas dalam upaya penanganan penyebab masalah, memperlihatkan dampak dari kegagalan hingga sampai akar penyebab permasalahn dan memberikan masukan bagi upaya improvisasi.

6) Improve

Pada tahapan ini, proses yang dikerjakan adalah melakukan berbagai upaya untuk mengeleminasi berbagai penyebab cacat produk atau kegagalan proses. Pada tahapan ini akan menyajikan usulan perbaikan dan pengendalian yang didapatkan dari interpretasi hasil. Setelah akar dari masalah penyebab kualitas teridentifikasi maka perlu dilakukan penetapan rencana tindakan untuk melaksanakan peningkatan kualitas.

7) Control

Tahap Control memiliki fungsi pengawasan dan monitoring terhadap rencana perbaikan yang telah dirancang dan dijadwalkan. Tim bertugas memastikan bahwa proses yang tengah berlangsung termasuk langkah-langkah improvisasinya adalah berada pada range yang ditetapkan atau tidak keluar dari batas-batas toleransi kualitas.

\section{Metodologi}

Pengumpulan data berupa data-data yang dibutuhkan dalam melakukan penelitian. Data yang dikumpulkan yaitu:
a. Data gambaran umum perusahaan
b. Data rekap produksi perusahaan
c. Data pengulangan proses/ketidaksuaian standar kualitas (rework) pada stasiun kerja pengeringan
d. Data ketetapan standar mutu teh hitam 
Data-data yang telah dikumupulkan selanjutnya diolah berdasarkan referensi yang relevan guna mencapai tujuan penelitian. Pengolahan data dilakukan menggunakan metode pengendalian kualitas (Quality Control) six sigma..

\section{Hasil dan Diskusi}

\subsection{Analisis Peta Kontrol $P$}

1. Pada grafik peta kontrol rework PF (Pecco Fanning) didapatkan ada 21 data berada di luar batas kontrol (out of control) yaitu pada bulan Agustus tanggal 2, 3, 4, 8, 9, 10, $11,12,13,15,18,20,22,23,24,25,26,27,28,29$ dan 30. Hal ini disebabkan banyaknya proporsi rework yang tidak terkontrol karena mesin di stasiun pengeringan yang tidak konsisten (incosistent) saat proses produksi sehingga terjadi perubahan nilai proporsi produksi dan rework yang tidak terkendali setiap harinya. Dari peta kontrol $\mathrm{p}$ yang sudah di revisi masih saja terdapat proporsi cacat yang cukup tinggi yaitu sebesar 0,046 atau 4,6\% sehingga perusahaan harus melakukan upaya atau strategi agar angka 4,6\% tersebut dapat turun menjadi $0 \%$ demi terciptanya tingkat maksimum cacat sebesar $0 \%$ sehingga tujuan perusahaan untuk zero defect dapat tercapai.

2. Data yang berada di luar batas kontrol harus di buang dan dilakukan revisi sehingga semua data berada dalam batas kontrol. Setelah data berada dalam batas kontrol maka nilai level sigma sudah dapat dihitung. Nilai CL yang didapat sebelum revisi yaitu 0,0442 sedangkan setelah dilakukan revisi didapatkan nilai CL yaitu 0,0387 sehingga data seluruhnya berada dalam batas kontrol. Data yang keluar dari batas kontrol haruslah dicari solusinya sehingga dapat dilakukan pencegahan pada periode selanjutnya sehingga hal tersebut tidak terulang kembali.

\subsection{Analisis Nilai Level Sigma dan DPMO}

Dari perhitungan nilai sigma yang dilakukan, didapatkan nilai Sigma untuk produksi teh hitam jenis PF (Pecco Fanning) memiliki nilai kapasitas sigma adalah 3,2661 $\approx 3,27$ (3-sigma) dengan DPMO 38690. Hal ini menunjukkan bahwa setiap satu juta kesempatan akan terdapat kemungkinan 38690 unit ketidaksesuian/produk rework.

Dengan demikian, dapat disimpulkan bahwa perlu dilakukan pengendalian kualitas yang lebih baik lagi untuk mengurangi jumlah produk rework sehingga nilai level sigma untuk PT. Perkebunan Nusantara VI Unit Usaha Danau Kembar dapat mencapai target level sigma maksimal.

\section{Kesimpulan}

Berdasarkan hasil dari perhitungan peta kendali proporsi rework, maka terlihat adanya data yang out of control. Terdapat 21 data yang diluar batas kontrol Sehingga dilakukanlah revisi. Dengan dilakukannya revisi ini, maka didapatkan data yang berada di dalam batas kendali. Artinya dengan banyaknya data yang out of control maka proporsi rework pada stasiun kerja pengeringan tidak terkendali sehingga perlunya solusi agar data proporsi rework berada dalam batas kontrol.

Hasil dari pendekatan Six Sigma yang telah dilakukan didapatkan level sig sigma yang berada pada level 3,2661 3,27 (3-sigma) dengan kemungkinan 38690 unit ketidaksesuaian/produk rework per satu juta produk sehingga perlunya dilakukan peningkatan kinerja agar produk rework yang dihasilkan dapat diminimumkan.

Penyebab rewok pada produk dipengaruhi oleh beberapa faktor seperti manusia, mesin, lingkungan kerja, dan metode.

\section{Referensi}

[1] Tannady, Hendy. 2015. Pengendalian Kualitas ed-1. Yogyakarta. Graha Ilmu.

[2] Assauri, Sofjan. 2008. Manajemen Produksi dan Operasi. Jakarta. Lembaga Penerbit Fakultas Ekonomi Universitas Indonesia. 
[3] Sugiyanto, D. 2015. Upaya Perbaikan Kualitas Proses Packing untuk Mengurangi Jumlah Cacat Kantong Pecah Dengan Metode Six Sigma DMAIC. Jurnal: Universitas Muhammadiyah Surakarta [4] Wahyuni, HC. 2015. Pengendalian Kualitas. Yogyakarta. Graha Ilmu. 